\title{
Outside-In Signaling in the Chondrocyte Nitric Oxide Disrupts Fibronectin-induced Assembly of a Subplasmalemmal Actin/Rho A/Focal Adhesion Kinase Signaling Complex
}

Robert M. Clancy, ${ }^{\star}$ John Rediske, ${ }^{\ddagger \S}$ Xiaoyin Tang, ${ }^{\star}$ Navdeep Nijher, ${ }^{\star}$ Sally Frenkel, ${ }^{*}$ Mark Philips, ${ }^{\ddagger}$ and Steven B. Abramson ${ }^{\star \ddagger}$ $*$ Department of Rheumatology, Hospital for Joint Diseases and ${ }^{\ddagger}$ Department of Medicine, Division of Rheumatology, NYU Medical Center, New York, New York 10003; and ${ }^{\S}$ Research Department, Pharmaceutical Division, Novartis Pharmaceuticals, Summit,

New Jersey 07091

\begin{abstract}
Elevated levels of fibronectin (Fn) in articular cartilage have been linked to the progression of both rheumatoid and osteoarthritis. In this study, we examined intracellular events which follow ligation of Fn to its receptor, the integrin $\alpha 5 \beta 1$. In addition, we examined the regulatory influence of nitric oxide on these events, since this free radical has been implicated in cartilage degradation. Exposure of chondrocytes to Fn-coated beads resulted in the circumferential clustering of the $\alpha 5 \beta 1$ integrin receptor, which was accompanied by the subplasmalemmal assembly of a focal activation complex comprised of F-actin, the tyrosine kinase, focal adhesion kinase (FAK), the ras related $G$ protein rho $\mathrm{A}$, as well as tyrosine-phosphorylated proteins. Treatment with exogenous nitric oxide (NO) or catabolic cytokines which induce nitric oxide synthase blocked the assembly of F-actin, FAK, rho A and tyrosine-phosphorylated proteins while not affecting the total number of beads bound per cell nor the clustering of $\alpha 5 \beta 1$ integrin. Use of a cGMP antagonist (Rp-8-Br cGMPS) or cGMP agonist (SpcGMPS) either abolished or mimicked the NO effect, respectively. Adherence of chondrocytes to fibronectin enhanced proteoglycan synthesis by twofold (vs. albumin). In addition, basic fibroblast growth factor (FGF) and insulin growth factor (IGF-1) induced proteoglycan synthesis in chondrocytes adherent to Fn but not albumin suggesting a costimulatory signal transduced by $\alpha 5 \beta 1$ and the FGF receptor. Both constitutive and FGF stimulated proteoglycan synthesis were completely inhibited by nitric oxide. These data indicate that the ligation of $\alpha 5 \beta 1$ in the chondrocyte induced the intracellular assembly of an activation complex comprised of the cytoplasmic tail of $\alpha 5 \beta 1$ integrin, actin, and the signaling molecules rho A and FAK. We show that NO inhibits the assembly of the intracellular activation complex and the synthesis of proteoglycans, but has no effect on the extracellular aggregation of $\alpha 5 \beta 1$ integrin. These observa-
\end{abstract}

Address correspondence to Robert Clancy, Department of Rheumatology, 301 E. 17th Street, New York, NY 10003. Phone: 212-5986173; FAX: 212-598-6168.

Received for publication 18 February 1997 and accepted in revised form 29 July 1997.

J. Clin. Invest.

(C) The American Society for Clinical Investigation, Inc. 0021-9738/97/10/1789/08 \$2.00

Volume 100, Number 7, October 1997, 1789-1796

http://www.jci.org tions provide a basis by which nitric oxide can interfere with chondrocyte functions by affecting chondrocyte-matrix interactions. (J. Clin. Invest. 1997. 100:1789-1796.) Key words: cartilage $\bullet$ extracellular matrix $\bullet$ integrin signaling • focal adhesion complex $\bullet$ cyclic GMP

\section{Introduction}

Cartilage homeostasis is regulated, in part, by the interaction of chondrocytes with extracellular matrix (ECM). ${ }^{1}$ Among the molecular interactions critical to the regulation is the interaction of chondrocyte integrins, particularly $\alpha 5 \beta 1$ with the multidomain ECM protein fibronectin (1-4). Integrins are heterodimeric glycoproteins known to transmit signals in both directions across the plasma membrane (5-7). In regulating cellular adhesion, cell activation signals are transmitted to integrins in an "inside-out" fashion such that the extracellular domains at the integrin molecules become adhesive (8). In addition, the binding of integrins to ECM proteins such as fibronectin (Fn) transmit outside-in signals resulting in cell activation that involves the formation of a multimolecular complex known as the focal adhesion plaques, which associates with the cytoplasmic domain of $\alpha 5 \beta 1$ integrin $(9,10)$. The assembly and disassembly of the focal adhesion plaque has been implicated in both inside-out and outside-in integrin signaling.

A dysregulation of cartilage homeostasis is evident in both inflammatory arthritis and osteoarthritis. We and others have implicated nitric oxide (NO) as a potential mediator of cartilage pathophysiology in arthritis (11-16). In the present study, we examine the cellular responses of chondrocytes to fibronectin and how these responses are modulated by NO. We show for the first time that the binding of fibronectin-coated beads to chondrocytes results in an outside-in signal involving accumulation of actin and associated protein assembly including the tyrosine kinase, focal adhesion kinase (FAK), the ras related $\mathrm{G}$ protein rho A, as well as tyrosine-phosphorylated proteins at the sites of the fibronectin-integrin complex. In addition, our studies indicate that NO, provided exogenously or produced endogenously in response to cytokines, prevents transmembrane responses after integrin ECM ligation. We show that the mechanism for the NO capacity to disassemble focal adhesion complexes is mediated by the cyclic GMPdependent pathway. These observations provide a basis by which NO can interfere with cartilage homeostasis by affecting chondrocyte extracellular matrix-dependent processes.

1. Abbreviations used in this paper: ECM, extracellular matrix; FAK, focal adhesion kinase; Fn, fibronectin; NIO, $N$-(L)-1 iminoethyl-L-ornithine. 


\section{Methods}

Culture of bovine chondrocytes. Bovine articular chondrocytes were obtained from the bovine fetlock joint as described (17). Briefly, slices of articular cartilage underwent digestion to isolate chondrocytes (hyaluronidase, trypsin, and collagenase). Cells were cultured in monolayer in DME plus 10\% FBS. Monolayer cultures of passage one bovine articular chondrocytes were plated onto coverslips and cultured in 24-well plates (105/well). These cells when placed in a 3-D matrix, produce type II collagen and stained positively for S-100 antigen consistent with the chondrocyte phenotype (18). In some experiments, cells were incubated with 8-bromoguanosine- $3^{\prime} 5^{\prime}$-cyclic monophosphorothioate, Rp-isomer (Rp-8Br-cGMPS; BioLog, La Jolla, $\mathrm{CA}$ ), guanosine-3'5'cyclic monophosphorothioate, Sp isomer (SpcGMPS; BioLog), 8-bromoguanosine-3'5' cyclic monophosphate (8-Br cGMP; Sigma Chemical Co., St. Louis, MO) mouse anti-human integrin $\alpha \mathrm{V} \beta 3$ (mAB 1976; Chemicon International, Inc., Temecula, CA), and mouse anti-human $\alpha 5 \beta 1$ (mAB 1969; Chemicon International, Inc.). The cells were used directly (as described below) or were cultured for $2 \mathrm{~d}$ with medium alone (DME $+0.2 \%$ FBS) or with a cytokine mixture containing $5 \mathrm{ng} / \mathrm{ml}$ human IL- $1 \alpha, 10 \mathrm{ng} / \mathrm{ml} \mathrm{TNF} \alpha$ and $100 \mathrm{U} / \mathrm{ml}$ bovine gamma interferon in the absence or presence of 100 $\mu \mathrm{M} N(5)-1-$ iminoethyl-L-ornithine (NIO; concentration varied).

Measurement of proteoglycan synthesis $\left({ }^{35} \mathrm{SO}_{4}\right.$ incorporation) by chondrocytes adhered to albumin or fibronectin-coated surfaces. Proteoglycan synthesis was determined by utilizing the method of Pennypacker and coworkers (19). Briefly, passage one cells $\left(3 \times 10^{6}\right.$ total $)$ were added to $75-\mathrm{cm}^{2}$ flasks which were previously coated overnight with either $1 \mathrm{mg} / \mathrm{ml}$ albumin (HSA; Armour Pharmaceutical Co., Tarrytown, NY) or $50 \mu \mathrm{g} / \mathrm{ml}$ fibronectin. The concentrations of albumin and fibronectin chosen for the coating of both plates $(1 \mathrm{mg} / \mathrm{ml} \mathrm{al-}$ bumin, $50 \mathrm{mg} / \mathrm{ml}$ fibronectin) and latex beads $(0.1 \mathrm{mg} / \mathrm{ml}$ albumin, $0.05 \mathrm{mg} / \mathrm{ml}$ fibronectin, see below) were selected based on their capacity to achieve saturation of plates (colorimetric assay) or beads (FACS ${ }^{\circledR}$ analysis). Cells were incubated in RPMI plus $0.5 \%$ FCS with or without nitric oxide $(0.1 \mathrm{M}$ in the presence or absence of $50 \mathrm{ng} / \mathrm{ml}$ fibroblast growth factor [FGF; Upstate Biotechnology Inc., Lake Placid, NY]) and $50 \mathrm{ng} / \mathrm{ml}$ insulin growth factor-1 (IGF-1; Sigma Chemical Co.). After $48 \mathrm{~h}, 1 \mu \mathrm{Ci} / \mathrm{ml} \mathrm{SO}_{4}\left(\mathrm{~S}-35 \mathrm{Na}_{2} \mathrm{SO}_{4}, 600-800 \mathrm{mCi} /\right.$ mmol; Amersham Corp., Arlington Heights, IL) was added for a 20-h pulse. Cells were then removed from the plates and were dialyzed separately, first against $0.1 \mathrm{M}\left(\mathrm{NH}_{4}\right)_{2} \mathrm{SO}_{4}$ for $3 \mathrm{~h}$ and then exhaustively against water. The radioactivity associated with the dialysate was determined by scintillation counting.

Analysis of iNOS and NO release. NO release was measured as nitrite in supernate at $24 \mathrm{~h}$ by using the Griess assay. To assess NOS protein expression, cell homogenate was prepared by scraping cells in Laemmli buffer and boiling for $5 \mathrm{~min}$. Protein was separated by $10 \%$ SDS gel. Western blot analysis utilized anti iNOS (Transduction Laboratories, Louisville, KY) after transfer to nitrocellulose and visualization by enhanced chemiluminescence.

Preparation of nitric oxide. Nitric oxide stock solutions were prepared by saturating a solution of isotonic buffer with nitric oxide as described (20). Alternatively, NO was delivered utilizing DETA/NO (Cayman Chemical Co., Ann Arbor, MI).

Bead assays. Latex beads (mean diameter $11.9 \mu \mathrm{m}$; Sigma Chemical Co.) were coated with ligands as described (21). Briefly, fibronectin or albumin (both from Sigma Chemical Co.) were dissolved at 0.1 $\mathrm{mg} / \mathrm{ml}$ in $10 \mathrm{mM}$ Tris $\mathrm{pH} 8.0,2 \mathrm{M} \mathrm{LiBr}, 1 \mathrm{mM}$ DTT. The mixture was incubated with latex beads $\left(10^{7} / \mathrm{ml} ; 1 \mathrm{~h}, 37^{\circ} \mathrm{C}\right)$ and then dialyzed against $100 \mathrm{vol}$ of $10 \mathrm{mM}$ acetate $\mathrm{pH} 5.5$ plus $0.4 \mathrm{mM}$ dithiothreitol. Beads were analyzed by FACS ${ }^{\circledR}$ (FACScan; Becton Dickinson, Mountain View, CA) after sequential treatment with rabbit anti-human fibronectin (Sigma Chemical Co.) and FITC-conjugated goat anti-rabbit IgG antibody (Sigma Chemical Co.). FACS ${ }^{\circledR}$ analysis revealed that the Fn-coated beads were uniformly coated with fibronectin while albumin beads were negative for fibronectin staining. The following antibodies were purchased and shown to be monospecific by
Western immunoblotting using goat anti-rabbit $\operatorname{IgG}$ conjugated with peroxidase or using rabbit anti-mouse IgG conjugated with peroxidase: anti integrin alpha subunit (AB 1928; Chemicon International, Inc.), anti-FAK (F 15020; Transduction Laboratories), antiphosphotyrosine (05321; Upstate Biotechnology, Inc.), anti-Raf (R 19120; Transduction Laboratories), anti-Rac 1 (SC217; Santa Cruz), antirho A (SC 418; Santa Cruz), antitubulin (T 3526; Sigma Chemical Co.) and anti-integrin $\beta 1$ subunit (4B4; Coulter Immunology, Hialeah, FL). Rhodamine-labeled phalloidin (R415) was purchased from Molecular Probes (Eugene, OR). Antibodies to $\beta 1$ integrin and $\alpha 5$ integrin subunits were purchased from Coulter Immunology (Immunotech) and Chemicon International, Inc., respectively.

Chondrocytes were incubated with beads $\left(1 \times 10^{5} /\right.$ well for a bead to cell ratio $=1.0 ; 20 \mathrm{~min}, 37^{\circ} \mathrm{C}$ ). Cells were washed, were fixed in PBS plus Ca with $4 \%$ paraformaldehyde, and triton X-100-treated cells were stained with rhodamine phalloidin or antibody. After reacting the latter with a secondary FITC conjugated antibody, samples were analyzed by immunofluorescence microscopy using a microscope (Nikon Inc., Melville, NY) equipped for fluorescein and rhodamine fluorescence and for a photographic recording of the data. In the scanning electron microscopy (SEM) experiments, cells were fixed in a buffer comprised of $2 \%$ glutaraldehyde, $0.1 \mathrm{M}$ cacodylate, $\mathrm{pH}$ 7.2, 0.1 M sucrose. Samples were coated with gold-palladium and analyzed by SEM using a scanning microscope (JSM-840; Joel U.S.A., Inc., Peabody, MA).

Data analysis. Data was reported as the mean and the standard error of the mean. The level of significance, $P$, of differences from the control experiments was calculated using the Student's $t$ test (twotailed).

\section{Results}

Attachment of fibronectin-coated beads induces colocalization of $\alpha 5 \beta 1$ and the signaling molecules rho $A$ and $F A K$ with actin at the subplasmalemma. To examine the intracellular events which follow integrin-ECM interactions, we selected a technique which utilizes latex beads coated with Fn or albumin. The exposure of chondrocytes to Fn-coated beads (20 min, $37^{\circ} \mathrm{C}$ ) resulted in the extracellular clustering of the integrin $\alpha 5$ subunit around the latex bead which was "mirrored" intracellularly by the localized accumulation of F-actin (Fig. 1). For Fn beads whose circumference was entirely located overlying the cell, the procedure allows quantitation of the percentage of beads with circumferential immunolocalization relative to the
FIBRONECTIN COATED BEADS
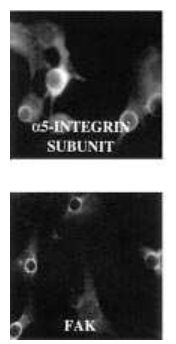
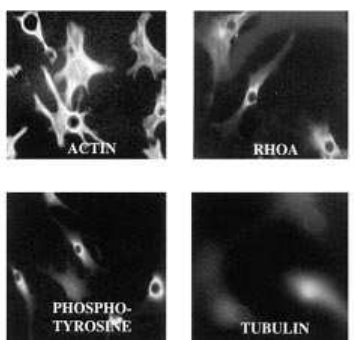

Figure 1. Attachment of fibronectin-coated beads induces colocalization of $\alpha 5 \beta 1$, actin, FAK, and rho A across the plasma membrane. Chondrocytes were adhered to cover slips and were exposed to fibronectin-coated beads or albumin-coated beads. After $20 \mathrm{~min}$, cells were washed, fixed in paraformaldehyde, stained for either $\alpha 5$ integrin subunit, actin, FAK, rho A, phosphotyrosine, or tubulin, as described in Methods and fluorescence was recorded by photography. 
total number of beads ( $\%$ positive beads). So analyzed, the F-actin response after Fn bead attachment yielded $73 \pm 1 \%$ positive beads. In contrast, exposure of bovine chondrocytes to albumin-coated beads did not induce clustering of $\alpha 5$ subunit of surface integrin. In addition, albumin beads did not elicit the local accumulation of actin at the bead contact site (Fig. 1).

Because both $\alpha \mathrm{V} \beta 3$ and $\alpha 5 \beta 1$ integrins bind fibronectin, we assessed the contribution of these integrins in our chondrocyte model. Inclusion of an anti- $\alpha 5 \beta 1$ blocking antibody (10 $\mu \mathrm{g} / \mathrm{ml}$ ) resulted in significant inhibition of the clustering of $\alpha 5$ subunit when chondrocytes were given Fn beads (Fig. 2). In addition, treatment with anti- $\alpha 5 \beta 1$ antibody resulted in complete inhibition of actin clustering which suggests that integrin signaling by chondrocytes given Fn beads is mediated by a $\beta 1$ integrin. In contrast to the results with anti- $\alpha 5 \beta 1$, a blocking anti- $\alpha \mathrm{V} \beta 3$ antibody had no effect on $\alpha 5$ and actin clustering.

Since recent studies in fibroblasts suggest that focal attachment points anchor signaling molecules such as the tyrosine kinase p125FAK (FAK) (21), we determined whether FAK colocalized with actin. We observed that the attachment of Fn

A.

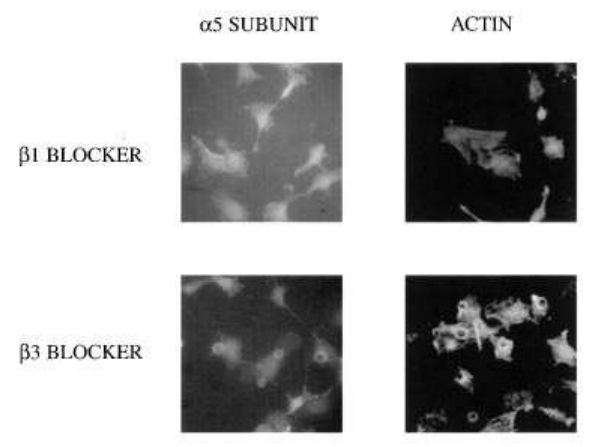

B.

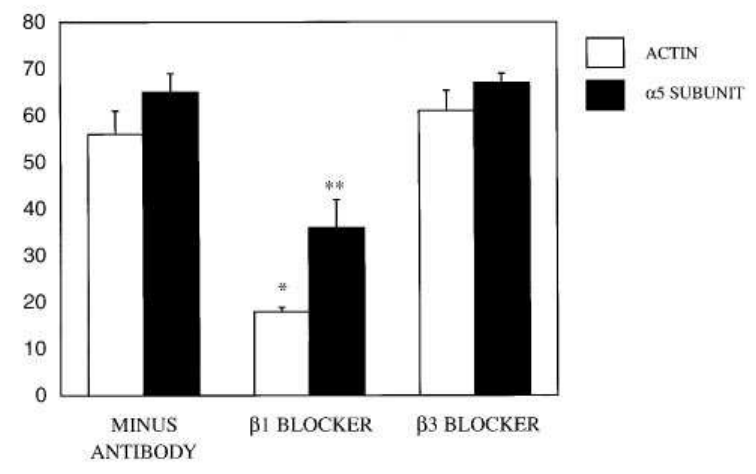

*p<0.001: *" p<0.05 vs minus antibodyx

Figure 2. Effect of anti- $\alpha 5 \beta 1$ integrin antibody and of anti- $\alpha \mathrm{V} \beta 3$ integrin antibody on the capacity to cluster $\alpha 5$ subunit and actin when chondrocytes were given Fn-coated beads. Cells on coverslips were preincubated in the absence (minus antibody) or presence of anti$\alpha 5 \beta 1 \mathrm{IgG}$ (complex specific, $\beta 1$ blocker) or anti- $\alpha \mathrm{V} \beta 3 \mathrm{IgG}$ (complex specific, $\beta 3$ blocker; both $30 \mathrm{~min}, 10 \mu \mathrm{g} / \mathrm{ml}, 37^{\circ} \mathrm{C}$ ) before the addition of Fn beads. Cells were stained for immunolocalization of proteins $(A)$. For Fn-coated beads whose circumference was entirely located within the cell, the percentage of beads with circumferential immunolocalization relative to the total number of beads (\% positive beads) was determined $(B)$. beads induced clusters of FAK, and that tyrosine phosphorylated proteins (possibly representing activation of FAK or another tyrosine kinase) were recruited to Fn bead contact sites (66 $\pm 4 \%$ positive beads; Fig. 1). Cells exposed to albumin beads did not stain positively for phosphotyrosine (not shown).

As shown in Fig. 1, Fn beads also induced clustering of another signaling molecule, the ras-related GTPase, rho A, a protein associated with signaling for actin stress fiber formation (22). Neither raf (not shown), nor tubulin (Fig. 1), a cytoskeletal protein, were detected at Fn bead contact sites. In addition, another ras-related $\mathrm{G}$ protein, rac1, failed to accumulate at contact sites of Fn-coated beads to chondrocytes (not shown).

Nitric oxide action on integrin-induced outside-in signaling. We have previously shown that NO in a dose-dependent manner prevents actin stress fiber formation and inhibits chondrocyte adherence to a fibronectin-coated surface (18). In the current study, we examined the effect of NO on the Fn-coated bead model of outside-in integrin signaling. Cells were treated with nitric oxide (10-100 $\mu \mathrm{M} ; 5 \mathrm{~min})$ before the addition of Fn beads. Fig. $3 A$ shows that NO treatment did not prevent the circumferential staining of the $\alpha 5 \beta 1$ integrin after the attachment of Fn beads. However, in the presence of NO, the circumferential staining of $\alpha 5 \beta 1$ integrin was not mirrored by an intracellular accumulation of actin at the site of bead attachment. Similarly, in the presence of NO, FAK did not colocalize with aggregated $\alpha 5 \beta 1$. These effects of $\mathrm{NO}$ were not due to cytotoxicity, based on a viability assay (18). In addition, if NO-treated cells were washed and allowed to recover $(1 \mathrm{~h})$, exposure to Fn beads did induce the colocalization of actin and associated proteins at the site of bead contact, indicating reversibility (not shown).

We next utilized the bead quantitation method to examine the dose-dependent effect of NO treatment (10-100 $\mu \mathrm{M}, 5 \mathrm{~min}$ $37^{\circ} \mathrm{C}$ ) before the addition of Fn-coated beads. As shown in Fig. $3 \mathrm{~B}$, treatment of chondrocytes with $30 \mu \mathrm{M}$ NO reduced actin and FAK accumulation to $25 \pm 7 \%$ control $(P<0.02)$ and $18 \pm 3 \%$ control $(P<0.001)$, respectively. NO treatment also reduced tyrosine phosphorylation by $>75 \%$ (not shown). NO did not inhibit total bead binding per cell (not shown). In contrast to its effects on assembly of the intracellular multiprotein complex, NO $(3-100 \mu \mathrm{M})$ did not prevent the extracellular aggregation of $\alpha 5 \beta 1$ integrin around the Fn beads (Fig. $3 \mathrm{~B}$ ). Thus, NO exerts an effect which sharply contrasts from the effects observed after treatment with the blocking $\beta 1$ antibody (which prevented $\alpha 5$ a subunit clustering (Fig. $2 A$ ). Taken together, the disruptive effect of NO on the assembly of F-actin/ FAK/rho focal activation complex is exerted at the interaction between $\alpha 5 \beta 1$ cytoplasmic domain and the focal activation complex components, not to an effect on the ability of $\alpha 5 \beta 1$ to cluster after interaction with extracellular ligand.

Nitric oxide effect depends upon the cGMP-dependent pathway. Cyclic GMP is an important mediator of NO actions (23). Interestingly, a cGMP-dependent protein kinase was recently described to be localized in the cytoskeletal fraction in endothelial cells and neutrophils and regulates cytoskeletal function $(24,25)$. To evaluate G-kinase in our system, we selected Rp-8-Br-cGMPS and Sp-cGMPS which selectively act as cGMP antagonist and agonist, respectively. In addition, we selected 8-Br cGMP which is a cell permeable cGMP analog. As shown in Table I, treatment with the antagonist completely blocked the capacity of NO to inhibit clustering of actin and 


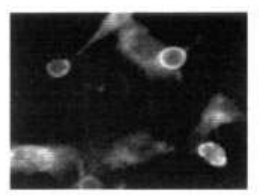

25 -INTEGRIN SUBUNIT

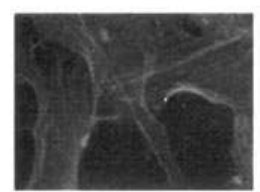

ACTIN

FAK
B.

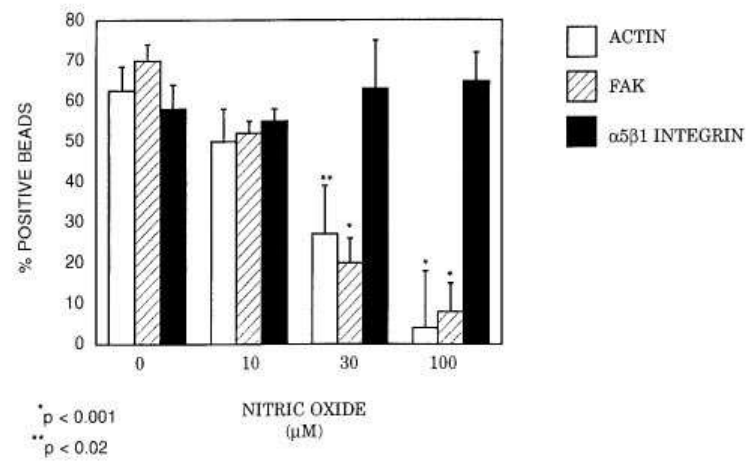

Figure 3. Nitric oxide blocks focal adhesion complex containing actin and FAK. Chondrocytes were treated with $0.1 \mathrm{mM}$ nitric oxide (5 $\left.\min , 37^{\circ} \mathrm{C}\right)$ and then incubated with Fn beads $\left(20 \mathrm{~min}, 37^{\circ} \mathrm{C}\right.$, see Methods). Cells were then fixed and stained for immunolocalization of actin and FAK as described in Methods $(A)$. Chondrocytes were adhered to cover slips then incubated with Fn-coated beads in the absence (control) or presence of nitric oxide (concentration varied, 5 $\min , 37^{\circ} \mathrm{C}$ ) before exposure to Fn-coated beads $(B)$. Cells were then stained for immunolocalization of proteins as described in Fig. 1. For Fn-coated beads whose circumference was entirely located within the cell, the percentage of beads with circumferential immunolocalization relative to the total number of beads ( $\%$ positive beads) was determined. Note that the disruptive effects of nitric oxide on the assembly of F-actin/FAK is exerted at the subplasmalemma and is not reflected in a similar disruption of the ligand (extracellular fibronectin)-receptor $(\alpha 5 \beta 1$ integrin) complex.

FAK by chondrocytes given Fn beads. In contrast, both Sp-cGMPS and 8-Br cGMP mimicked the NO action to inhibit formation of focal adhesion complex in a dose-dependent manner.

Catabolic cytokines prevent Fn-induced assembly of the focal adhesion complex. We next assessed the effect of endogenously produced NO on integrin signaling. Cells were preincubated for $48 \mathrm{~h}$ in the presence or absence of a mixture of cytokines (5 ng/ml IL- $1 \alpha, 10 \mathrm{ng} / \mathrm{ml} \mathrm{TNF-} \alpha, 100 \mathrm{U} / \mathrm{ml} \gamma$-INF), known to promote the upregulation of iNOS and the production of NO in these cells (18). For specificity, studies were performed in the presence or absence of the nitric oxide synthase inhibitor, $N$-(L)-1 iminoethyl-L-ornithine (NIO). The nitric oxide synthase inhibitor reduced cytokine stimulated NO release from 9.2 to $0.9 \mu \mathrm{M}$ at $48 \mathrm{~h}$. As shown in Fig. 4, the circumferential staining for the $\alpha 5 \beta 1$ integrin after exposure to Fn beads was unaffected by cytokine treatment. In contrast, cytokine treatment prevented the formation of the intracellular multiprotein focal activation complex as reported by the circumfer-
Table I. NO Inhibits $\beta 1$ Integrin Signaling via Activation of cGMP-dependent Protein Kinase

\begin{tabular}{llcc}
\hline & \multicolumn{3}{c}{$\%$ Positive beads } \\
\cline { 2 - 4 } & $\alpha 5 \beta 1$ & ACTIN & FAK \\
\hline Control & $78 \pm 8$ & $73 \pm 1$ & $70 \pm 7$ \\
NO & $83 \pm 6$ & $5 \pm 5^{*}$ & $8 \pm 5^{*}$ \\
NO + Rp-8-Br cGMPS & $77 \pm 5$ & $70 \pm 4$ & $75 \pm 9$ \\
Rp-8-Br cGMPS & $85 \pm 10$ & $68 \pm 7$ & $64 \pm 7$ \\
Sp-cGMPS, 1.0 mM & $70 \pm 8$ & $15 \pm 4^{*}$ & $36 \pm 3^{\ddagger}$ \\
Sp-cGMPS, 0.3 mM & $62 \pm 10$ & $44 \pm 7$ & $69 \pm 4$ \\
8-Br cGMP, 1.0 mM & $64 \pm 4$ & $12 \pm 2^{*}$ & $27 \pm 1^{*}$ \\
8-Br cGMP, 0.3 mM & $62 \pm 7$ & $25 \pm 3^{*}$ & $26 \pm 4^{*}$ \\
8-Br cGMP, 0.1 mM & $67 \pm 8$ & $60 \pm 2$ & $68 \pm 2$ \\
\end{tabular}

Chondrocytes were adhered to cover slips and incubated under varied conditions with the NO donor drug DETA/NO $(0.1 \mathrm{mM}, 4 \mathrm{~h})$, the cGMP-dependent protein kinase inhibitor, guanosine-3'5'-monophosphorothioate, Rp-isomer (Rp-8-Br-cGMPS, $0.1 \mathrm{mM}, 40 \mathrm{~min}$ ), the cGMP-dependent protein kinase activator, guanosine-3'5'-monophosphorothioate, Sp-isomer (Sp-cGMPS, concentration varied, $40 \mathrm{~min}$ ), and the cGMP agonist 8-bromoguanosine- $3^{\prime} 5^{\prime}$ cyclic monophosphate (8-Br-cGMP, concentration varied, $40 \mathrm{~min}$ ). Cells were then incubated with Fn beads $\left(20 \mathrm{~min}, 37^{\circ} \mathrm{C}\right)$. Cells were fixed in glutaraldehyde and analyzed by immunofluorescence (see Methods) after staining the cells with anti- $\alpha 5$-integrin $(\alpha 5 \beta 1)$, rhodamine phalloidin $(A C T I N)$ or antiFAK $(F A K)$; vs. control. ${ }^{*} P<0.01 ;{ }^{\ddagger} P<0.05$.

ential staining for FAK, phosphoprotein, rho, or actin. F-actin accumulation at the bead contact site was reduced by cytokine treatment to $15 \pm 5 \%$ positive beads $(P<0.006$ vs. control $)$. Cytokine treatment also resulted in similar decreases in FAK and rho colocalization and in tyrosine phosphorylation which were $11 \pm 3 \%(P<0.015), 20 \pm 1 \%(P<0.006)$, and $8 \pm 1 \%$ $(P<0.015)$ of control (Fig. 4, Table II), respectively. The decrease in staining for cytoskeletal associated proteins was not due to effects on bead attachment, since cytokine treatment did not reduce the number of beads bound per cell (Table II). The inhibition of FAK translocation and tyrosine phosphorylation caused by cytokine treatment were completely reversed when cells were incubated in the presence of the NO synthase inhibitor, 1-N5-1-iminoethylornithine (NIO). In contrast, cotreatment with NIO did not prevent the inhibitory cytokine effects on F-actin and rho A accumulation (Fig. 4, Table II). However, as shown in Table II, treatment with the kinase inhibitor, Rp-8-Br cGMPS completely blocked the capacity of cytokines to inhibit clustering of actin and rho A by chondrocytes given Fn-beads.

Nitric oxide inhibits proteoglycan synthesis in chondrocytes adhered to a fibronectin-coated surface. To determine the effects of fibronectin ligation and NO on cartilage metabolism in resting and stimulated cells (by treatment with basic fibroblast growth factor [FGF] or with insulin growth factor-1 [IGF-1]), proteoglycan synthesis was assessed utilizing cells incubated on plates coated with either albumin or fibronectin. Proteoglycan synthesis, measured as ${ }^{35} \mathrm{SO}_{4}$ incorporation, was determined in the presence or absence of FGF or IGF-1. As shown in Fig. 5, proteoglycan synthesis by chondrocytes adherent to albumin was not increased by FGF or by IGF-1 treatments. In contrast, proteoglycan synthesis increased twofold when chon- 
$\alpha 5$ INTEGRIN SUBUNIT
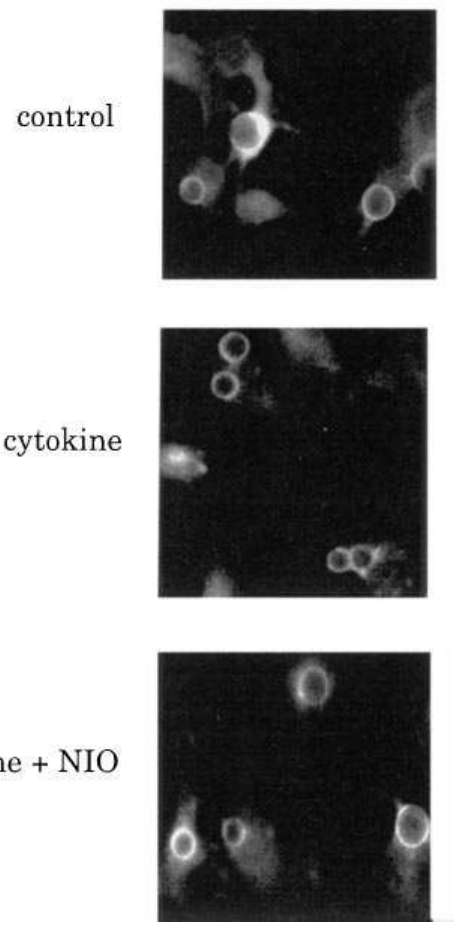

PHOSPHOTYROSINE
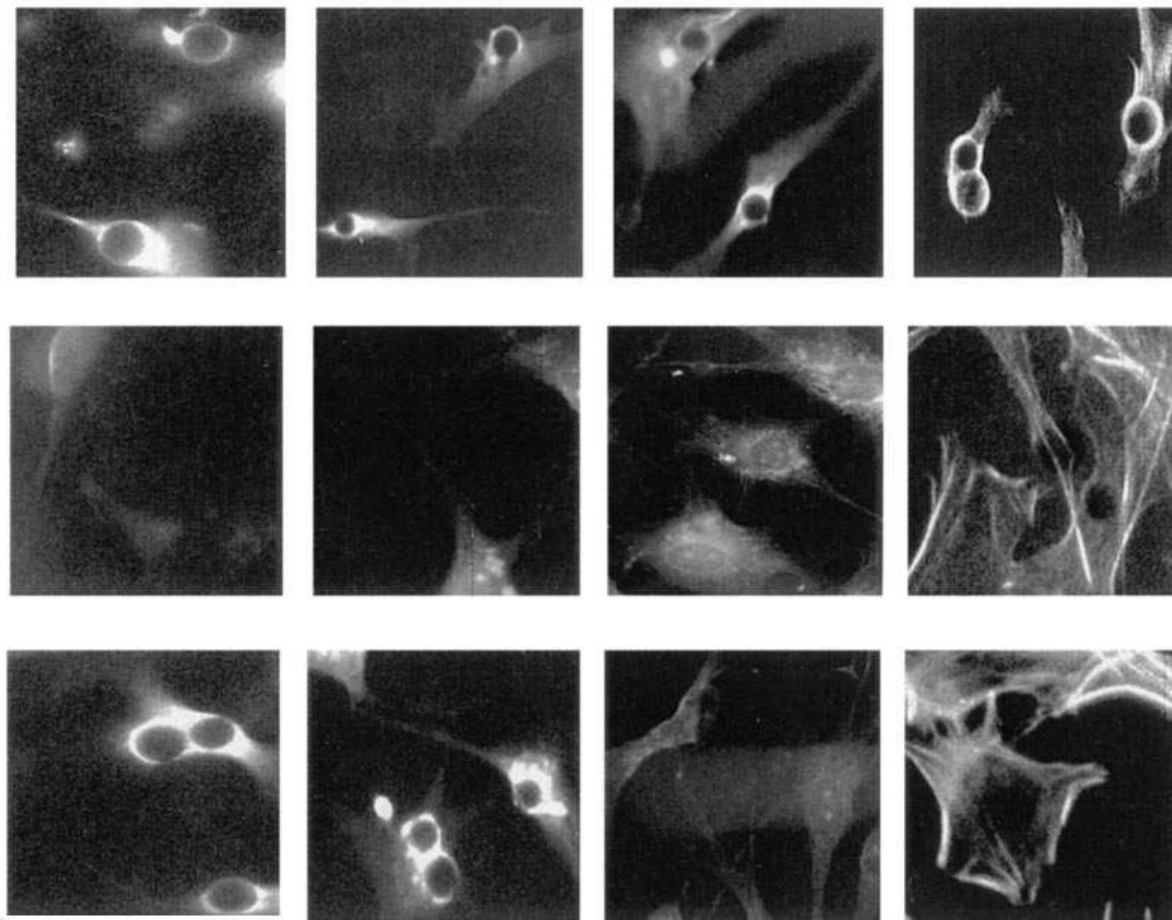
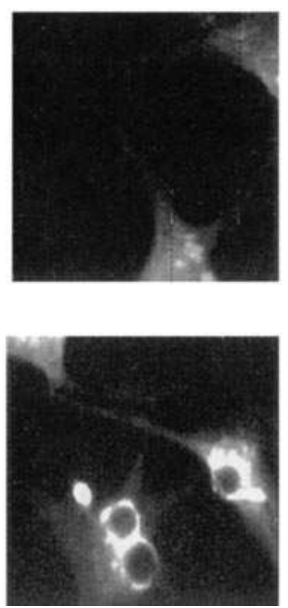
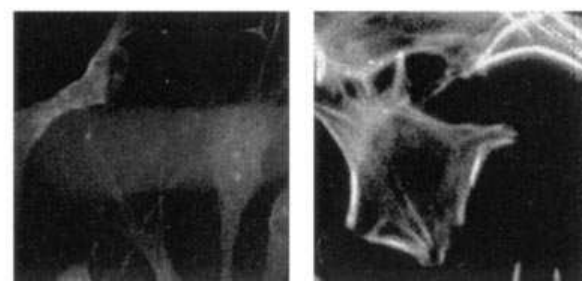

Figure 4. Cytokine treatment which induces NO by these cells inhibits integrin-induced "outside-in" signaling. Chondrocytes were adhered to cover slips then incubated in the absence (control) or presence (cytokine) of treatment with catabolic cytokines ( $48 \mathrm{~h}$ ) and a nitric oxide synthase inhibitor 1-N5-1-iminoethylornithine (NIO). Cells were then incubated with Fn-coated beads and processed as described in Fig. 1 for staining with F-actin, rho A, FAK, tyrosine phosphorylated proteins, and $\alpha 5$ subunit of $\alpha 5 \beta 1$ integrin (See Table II for analysis of data).

drocytes were grown on a fibronectin-coated surface $(P<$ $0.01)$. Treatment with FGF and IGF-1 further enhanced proteoglycan synthesis by twofold $(P<0.05$ vs. Fn) and sevenfold $(P<0.01$ vs. Fn $)$, respectively. The exposure of chondrocytes adherent to fibronectin with NO significantly blocked the fibronectin-dependent increase in proteoglycan synthesis by both control, FGF- and IGF-1-treated groups. NO did not affect the baseline proteoglycan production by chondrocytes adherent to albumin (not shown). Thus, these data indicate that the ligation of fibronectin by chondrocytes induces an intracellular signal that promotes both constitutive and FGF stimu- lated proteoglycan synthesis. NO, possibly by preventing the assembly of a complete focal activation complex which colocalizes with the cytoplasmic tail of $\alpha 5 \beta 1$, blocks that signal.

\section{Discussion}

Our studies demonstrate that the response of chondrocytes exposed to Fn-latex beads include the extracellular clustering of $\alpha 5 \beta 1$ integrin and the intracellular aggregation of actin and associated protein assembly. These responses were inhibited by an anti- $\alpha 5 \beta 1$ antibody but not by an anti- $\alpha \mathrm{V} \beta 3$ antibody sug-

Table II. Quantitation of Percentage of Cells which Bind Beads and of the Bead-induced $\beta 1$ Integrin Signaling by Chondrocytes with or without Cytokine and Nitric Oxide Synthase Inhibitor

\begin{tabular}{|c|c|c|c|c|c|c|}
\hline & \multirow{2}{*}{$\begin{array}{l}\text { Percentage of cells binding } \\
\text { at least } 1 \text { bead }\end{array}$} & \multicolumn{5}{|c|}{$\%$ Positive beads } \\
\hline & & $\alpha$ Integrin subunit & ACTIN & FAK & Phosphotyrosine & RhoA \\
\hline Control & $39 \pm 8$ & $78 \pm 8$ & $73 \pm 1$ & $70 \pm 7$ & $66 \pm 4$ & $78 \pm 5$ \\
\hline NIO & $35 \pm 14$ & $75 \pm 5$ & $78 \pm 3$ & $82 \pm 4$ & $69 \pm 4$ & $82 \pm 4$ \\
\hline Cytokine & $51 \pm 8$ & $79 \pm 7$ & $15 \pm 5^{*}$ & $11 \pm 3^{\ddagger}$ & $8 \pm 1^{\ddagger}$ & $20 \pm 1^{\ddagger}$ \\
\hline Cytokine + NIO & $63 \pm 10$ & $72 \pm 5$ & $7 \pm 4 *$ & $71 \pm 1$ & $75 \pm 3$ & $10 \pm 2 *$ \\
\hline Cytokine $+\mathrm{Rp}-8-\mathrm{Br}$ cGMPS & ND & $75 \pm 8$ & $89 \pm 9$ & $76 \pm 3$ & $53 \pm 4$ & $74 \pm 3$ \\
\hline
\end{tabular}

Chondrocytes were adhered to cover slips and incubated under varied conditions for $48 \mathrm{~h}$. Cells were then incubated with Fn beads $\left(20 \mathrm{~min}, 37^{\circ} \mathrm{C}\right)$. Cells were fixed in glutaraldehyde and analyzed by SEM and immunofluorescence as described (see Methods); vs. control ${ }^{*} P<0.006$; ${ }^{\ddagger} P<0.015$. 


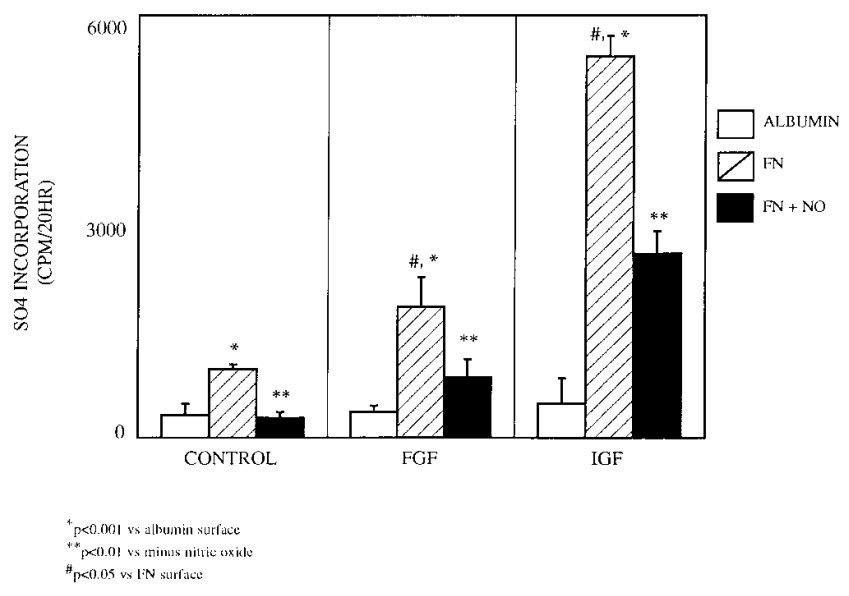

Figure 5. Nitric oxide inhibits proteoglycan synthesis in chondrocytes adhered to a fibronectin-coated surface. Chondrocytes were incubated on plates which were coated with either albumin or fibronectin. Cells were incubated $(48 \mathrm{~h})$ in the presence or absence of FGF and IGF-1 with or without NO (0.1 M; added daily). Radiolabeled S04 incorporation was determined during the final $20 \mathrm{~h}$ of incubation.

gesting a causal relationship between the ligation of $\alpha 5 \beta 1$ integrins and fibronectin-integrin signaling. Our studies are consistent with those of Loeser (27) who examined the effect of blocking antibodies on chondrocyte adherence to a fibronectin-coated surface and found that adhesion was inhibited by an anti- $\beta 1$ antibody but not by an anti- $\beta 3$ antibody. The ligation of $\beta 1$ integrins thus results in the assembly of a characteristic transmembrane adhesive complex. We have identified important candidates for mediating signal transduction which follows $\alpha 5 \beta 1$ ligation. For example, we show that the tyrosine kinase P125FAK (FAK) is recruited to focal complexes upon attachment of cells to the ECM. The function of FAK is unclear, although it can act to recruit $\mathrm{SH} 2$-containing proteins such as src and grb-2, the adaptor protein for the ras guanine exchange factor SOS (9). Another important observation of our study was that rho A, the ras-related GTPase, is recruited to focal complexes upon attachment of cells to ECM. Interestingly, using Swiss 3 T3 fibroblasts, as a model system, Hall and coworkers used a microinjection technique to show that rho A was responsible for regulating a pathway which stimulated actin polymerization and the formation of a unique phenotype (stress fibers) (28-30).

Regarding cell function, basic FGF has previously been shown to stimulate proteoglycan synthesis $(31,32)$. Our data indicate that the signal transduced after extracellular ligation of fibronectin not only increases proteoglycan synthesis above baseline, but appears to be required for these cells to increase proteoglycan synthesis in response to FGF and IGF-1. In addition, our results are concordant with recent studies which indicate that the stabilization of cell adhesion via integrin ligation can regulate the phosphorylation and activation of growth factor receptors, such as the receptor for FGF and IGF-1 (33).

Our studies also examined the effect of NO, which is produced in micromolar quantities by both rheumatoid and osteoarthritic cartilage $(12,15,34)$, on the interaction between the chondrocyte and fibronectin. Previous studies have indi- cated that chondrocyte adhesion and matrix synthesis are inhibited by NO $(14,16,18)$. Our data demonstrate that nitric oxide exerts profound inhibitory effects on fibronectin $\alpha 5 \beta 1$ signaling. These effects can be summarized as follows: (a) NO inhibited actin polymerization and the translocation from cytosol to plasmamembrane of two-key signaling molecules, FAK and rho $\mathrm{A}$, at the site of $\alpha 5 \beta 1$ ligation; this inhibition did not prevent the extracellular ligation of fibronectin by $\alpha 5 \beta 1 ;(b)$ NO inhibited the activation of a tyrosine kinase, possibly FAK; (c) Finally, NO inhibited the capacity of fibronectin to increase proteoglycan synthesis in both control and FGF-treated cells. Studies utilizing the specific inhibitor of the cGMP-dependent protein kinase, Rp-8-Br-cGMPS, suggest that the effects of $\mathrm{NO}$ on the focal adhesion complex may be due to its capacity to raise cGMP as occurs in other cell types.

The approach we utilized to examine proteoglycan synthesis by chondrocytes was intended to test whether integrin signaling contributes to both constitutive and growth factor-stimulated cell function. We found that NO inhibited the capacity of cells grown on a fibronectin-coated surface to increase proteoglycan synthesis in both control and stimulated cells in association with the capacity of NO to inhibit integrin signaling. It is important to note that the regulation of proteoglycan synthesis is complex, and there may be several explanations for the data not directly related to effects on integrin signaling, including effects of fibronectin on other matrix protein secretion by chondrocytes. However, we recently obtained evidence that Fn beads stimulate mitogen associated protein (MAP) kinase within 30 min of exposure and that NO attenuates the Fn bead effect on MAP kinase (unpublished observation). The elucidation of the relationship among integrin signaling, MAP kinase, and proteoglycan synthesis is currently under investigation.

In our experiments the inhibitory effects of $\mathrm{NO}$ were observed at concentrations which are achieved intraarticularly in both osteoarthritis and rheumatoid arthritis (35). To determine whether endogenous NO acted in a possible autocrine fashion on the $\alpha 5 \beta 1$ signaling, chondrocytes were exposed to catabolic cytokines in the presence or absence of the NOS inhibitor, NIO. In these studies, we could demonstrate that cytokine treatment, like exogenous NO, inhibited integrin signaling by dissociating the actin-FAK complex at the subplasmalemma. Decreases in FAK accumulation and tyrosine phosphorylation were completely reversed when the cells were incubated with cytokines in the presence of the NO synthase inhibitor, 1-N5-1-iminoethyl ornithine. In contrast, the cytokine effects on F-actin and rho A were only partially reversed. These experiments indicate that FAK translocation and tyrosine phosphorylation are dependent upon cytokine induction of NO synthesis. In addition, the data suggest that FAK associates with $\alpha 5 \beta 1$ independent of its colocalization with actin or Rho A. The apparent qualitative differences between $\mathrm{NO}$ and cytokines on the assembly of the focal adhesion complex are not yet fully understood. The inability of NIO to reverse cytokine effects on actin or rho A suggests: $(a)$ either that NO inhibition is incomplete, or $(b)$ that other factors produced in response to cytokine stimulation exert similar inhibitory effects on the formation of focal adhesion complex. The capacity of the cGMP antagonist, Rp- $8 \mathrm{Br}$ cGMPS to reverse the cytokine response suggests that in the presence of NMMA, low levels of NO are produced by cytokine treated cells sufficient to generate cGMP which acts intracellularly via a cGMPdependent pathway (probably G-kinase). 
In interpreting our studies, it is important to note that the biological activity of fibronectin can change dramatically depending on matrix composition (36). For example, the exposure of fibroblasts to a mixture of fibronectin and the matrix molecule tenascin results in the disassembly of F-actin and other components of the focal adhesion structures (37) and a concomitant cell detachment. Interestingly, this matrix environment shifts signaling from those associated with polymerization of actin to the recruitment of a serine-threonine kinase (cyclic GMP dependent protein kinase, PKG [25]); While fibronectin alone inhibits collagenase synthesis (noted above), fibronectin plus tenascin promotes an expression of matrix metalloproteinase (MMPs) (collagenase) (38). These studies suggest that the $\beta 1$ integrin fibronectin interaction may trigger at least two separate signal transduction pathways which result in the localized expression of MMPs for the removal or remodeling of matrices that are no longer functional or to facilitate cell migration. Whether NO plays a similar role as tenascin, i.e., an antiadhesive molecule, and modifies fibronectin-mediated responses remains to be addressed.

A full understanding of the mechanism by which NO interferes with the assembly of the focal adhesion complex also remains to be determined. As noted above, we show that the capacity of NO to prevent assembly of focal adhesion complex is reversed by an inhibitor of the cGMP-dependent protein kinase. These data are consistent with a broad role of cGMPdependent protein kinase in the regulation of protein assembly at focal adhesion complexes. Murphy-Ullrich and coworkers (25) recently demonstrated that cGMP-dependent protein kinase is required for thrombospondin or tenasin-dependent focal adhesion disassembly and cytoskeletal reorganization. In addition, NO may exert this effect via its capacity to stimulate ADP-ribosylation reactions. We have previously shown that NO inhibits actin polymerization in human neutrophils via promoting ADP-ribosylation reactions $(39,40)$. The capacity of NO to regulate the integrin-dependent signal transduction pathway via its action to stimulate ADP-ribosylation of actin or rho A in chondrocytes is currently under investigation. Alternatively, NO may block the assembly of focal adhesion complex via an action which inhibits the enzyme activity of protein kinases other than cGMP-dependent protein kinase. Danen et al. (8) examined cellular parameters necessary for the activation of the integrin $\alpha 5 \beta 1$ in the K562 cell line, which in the absence of stimulation with PMA fail to adhere to fibronectin coated surfaces. Treatment with PMA stimulates adherence, which in part, is due to the phosphorylation of $\beta 1$ integrins by protein kinase $\mathrm{C}$ (PKC). Interestingly, NO has been reported to inhibit PKC activity (41).

What are the implications of these findings for disease? In osteoarthritis there is a loss of cartilage matrix which is accompanied by an increased expression of $\beta 1$ integrins and fibronectin $(3,4,42-44)$. The effects of this increase of both ligand and receptor in the disease process are unclear. However, the increase may reflect a reparative attempt to remodel degenerative cartilage via an integrin generated signal. Our data demonstrate that the assembly of a multiprotein activation complex at sites of $\beta 1$ integrin ligation is associated with increased proteoglycan synthesis. We show for the first time in any cell type that NO and NO-inducing cytokines interfere with the assembly of the activation complex. We speculate that the capacity of NO to inhibit Fn-dependent synthesis may be, in part, due to disruption of the subplasmalemmal signaling complex.

\section{Acknowledgments}

We thank Dr. Sabatini of the Department of Cell Biology at New York University Medical Center for permitting us to use the scanning electron and fluorescent microscopes. We thank Dr. Edith Robbins for her help in the interpretation of the scanning electron micrographs. We thank Dr. Michael Pillinger for analyzing chondrocyte lysates for MAP kinase activity.

Funding of this work was provided by a Biomedical Science Grant from the National Arthritis Foundation to S.B. Abramson. Special thanks to the Joseph and Sophia Abeles Foundation and The Jane Falk Fund in the Westchester Community Foundation for their contributions to support our work. We also acknowledge the support of a research grant from the Tobacco Research Council to M. Philips.

\section{References}

1. Woods, V.L.J., P.J. Schreck, D.S. Gesink, H.O. Pacheco, D. Amiel, W.H. Akeson, and M. Lotz. 1994. Integrin expression by human articular chondrocytes. Arthritis \& Rheum. 37:537-544.

2. Burton-Wurster, N., M. Butler, S. Harter, C. Colombo, J. Quintavalla, D. Swartzendurber, C. Arsenis, and G. Lust. 1986. Presence of fibronectin in articular cartilage in two animal models of osteoarthritis. J. Rheum. 13:175-182.

3. Loeser, R.F., C.S. Carlson, and M.P. McGee. 1995. Expression of beta1 integrins by cultured articular chondrocytes and in osteoarthritic cartilage. Exp. Cell Res. 217:248-257.

4. Rees, J.A., S.Y. Ali, and R.A. Brown. 1987. Ultrastructural localisation of fibronectin in human osteoarthritic articular cartilage. Ann. Rheum. Dis. 46: $816-822$.

5. Albelda, S.M., and C.A. Buck. 1990. Integrins and other cell adhesion molecules. FASEB J. 4:2868-2880.

6. Ruoslahti, E., and J.C. Reed. 1994. Anchorage dependence, integrins, and apoptosis. Cell. 77:477-478.

7. Hynes, R.O. 1987. Integrins: a family of cell surface receptors. Cell. 48: 549-554.

8. Danen, E.H., S. Aota, A.A. Van Kraats, K.M. Yamada, D.J. Ruiter, and G.N. Van Muijen. 1995. Requirement for the synergy site for cell adhesion to fibronection depends on the activation state of integrin alpha5 beta1. J. Biol. Chem. 270:21612-21618.

9. Clark, E.A., and J.S. Brugge. 1995. Integrins and signal transduction pathways: the road taken. Science (Wash. DC). 268:233-239.

10. Curtis, A.S., M. McGrath, and L. Gasmi. 1992. Localised application of an activating signal to a cell: experimental use of fibronectin bound to beads and the implications for mechanisms of adhesion. J. Cell Sci. 101:427-436.

11. Maier, R., G. Bilbe, J. Rediske, and M. Lotz. 1994. Inducible nitric oxide synthase from human articular chondrocytes: cDNA cloning and analysis of mRNA expression. Biochim. Biophys. Acta. 1208:145-150.

12. Amin, A.R., P.E. Di Cesare, P. Vyas, M. Attur, E. Tzeng, T.R. Billiar, S.A. Stuchin, and S.B. Abramson. 1995. The expression and regulation of nitric oxide synthase in human osteoarthritic-affected chondrocytes: evidence for upregulated neuronal nitric oxide synthase. J. Exp. Med. 182:2097-2102.

13. Murrell, G.A., M.M. Doland, D. Jang, C. Szabo, R.F. Warren, and J.A. Hannafin. 1996. Nitric oxide: an important articular free radical. J. Bone J. Surg. 78A:265-274.

14. Stadler, J., M. Stefanovic-Racic, T.R. Billiar, R.D. Curran, L.A. McIntyre, H.I. Georgescu, R.L. Simmons, and C.H. Evans. 1991. Articular chondrocytes synthesize nitric oxide in response to cytokines and lipopolysaccharide. $J$. Immunol. 147:3915-3920.

15. Stefanovic-Racic, M., J. Stadler, and C. H. Evans. 1993. Nitric oxide and arthritis. Arthritis \& Rheum. 36:1036-1044.

16. Taskiran, D., M. Stefanovic-Racic, H. Georgescu, and C. Evans. 1994. Nitric oxide mediates supression of cartilage proteoglycan synthesis by interleukin-1. Biochem. Biophys. Res. Commun. 200:142-148.

17. Rediske, J., C. Kohne, B. Zhang, and M. Lotz. 1994. The inducible production of nitric oxide by articular cell types. Osteoarth. \& Cartilage. 2:199-206.

18. Frenkel, S.R., R.M. Clancy, J.L. Ricci, P.E. Di Cesare, J.J. Rediske, and S.B. Abramson. 1996. Effect of nitric oxide on chondrocyte migration, adhesion and cytoskeletal assembly. Arthritis \& Rheum. 39:1905-1912.

19. Pennypacker, J.P., J.R. Hassell, K.M. Yamada, and R.M. Pratt. 1979. The influence of an adhesive cell surface protein on chondrogenic expression in vitro. Exp. Cell Res. 121:411-415.

20. Clancy, R.M., Y. Miyazaki, and P.J. Cannon. 1990. Use of thionitrobenzoic acid to characterize the stability of nitric oxide in aqueous solutions and in porcine aortic endothelial cell suspensions. Anal. Biochem. 191:138-143.

21. Miyamoto, S., S.K. Akiyama, and K.M. Yamada. 1995. Synergistic roles for receptor occupancy and aggregation in integrin transmembrane function. Science (Wash. DC). 267:883-885. 
22. Hall, A. 1990. The cellular functions of small GTP-binding proteins. Science (Wash. DC). 249:635-640.

23. Waldman, S.A., and F. Murad. 1988. Biochemical mechanisms underlying vascular smooth muscle relaxation: the guanylate cyclase-cyclic GMP system. J. Cardiovasc. Pharmacol. 12 (Suppl.) 5:S115-S118.

24. Wyatt, T.A., T.M. Lincoln, and K.B. Pryzwansky. 1991. Vimentin is transiently co-localized with and phosphorylated by cyclic GMP-dependent protein kinase in Formyl-peptide-stimulated neutrophils. J. Biol. Chem. 266: 21274-21280.

25. Murphy-Ullrich, J.E., M.A. Paliero, N. Boerth, J.A. Greenwood, T.M. Lincoln, and T.L. Cornwell. 1996. Cyclic GMP-dependent protein kinase is required for thrombospondin and tenascin mediated focal adhesion disassembly. J. Cell Sci. 109:2499-2508.

26. Butt, E., D. Pohler, H.G. Genieser, J.P. Huggins, and B. Bucher. 1995. Inhibition of cyclic GMP-dependent protein kinase-mediated effects by (Rp)-8bromo-PET-cyclic GMPS. Br. J. Pharmacol. 116:3110-3116.

27. Loeser, R.F. 1993. Integrin-mediated attachment of articular chondrocytes to extracellular matrix proteins. Arthritis \& Rheum. 36:1103-1110.

28. Ridley, A.J., and A. Hall. 1992. The small GTP-binding protein Rho regulates the assembly of focal adhesions and actin stressed fibers in response to growth factors. Cell. 70:389-399.

29. Ridley, A.J., H.F. Paterson, C.L. Johnston, D. Diekmann, and A. Hall. 1992. The small GTP-binding protein rac regulates growth factor-induced membrane ruffling. Cell. 70:401-410.

30. Nobes, C.D., and A. Hall. 1995. Rho, rac, and cdc42 GTPases regulate the assembly of mutimolecular focal complexes associated with actin stress fibers, lamellipodia, and filopodia. Cell. 81:53-62.

31. Prins, A.P., J.M. Lipman, C.A. McDevitt, and L. Sokoloff. 1982. Effect of purified growth factors on rabbit articular chondrocytes in monolayer culture. Arthritis \& Rheum. 25:1228-1238.

32. Osborn, K.D., S.B. Trippel, and H.J. Mankin. 1989. Growth factor stimulation of adult articular cartilage. J. Orthop. Res. 7:35-42.

33. Miyamoto, S., H. Teramoto, J.S. Gutkind, and K.M. Yamada. 1996. Integrins can collaborate with growth factors for phosphorylation of receptor tyrosine kinases and MAP kinase activation: roles of integrin aggregation and oc- cupancy of receptors. J. Cell Biol. 135:1633-1642.

34. Clancy, R.M., and S.B. Abramson. 1995. Nitric oxide: a novel mediator of inflammation. Proc. Soc. Exp. Biol. Med. 210:93-108.

35. Farrell, A.J., D.R. Blake, R.M. Palmer, and S. Moncada. 1992. Increased concentrations of nitrite in synovial fluid and serum samples suggest increased nitric oxide synthesis in rheumatic diseases. Ann. Rheum. Dis. 51:12191222

36. Chiquet-Ehrismann, R., P. Kalla, C.A. Pearson, K. Beck, and M. Chiquet. 1988. Tenascin interferes with fibronectin action. Cell. 53:383-390.

37. Murphy-Ullrich, J.E., V.A. Lightner, I. Aukhil, Y.Z. Yan, H.P. Erickson, and M. Hook. 1991. Focal adhesion integrity is downregulated by the alternatively spliced domain of human tenascin. J. Cell Biol. 115:1127-1136.

38. Tremble, P., R. Chiquet-Ehrismann, and Z. Werb. 1994. The extracellular matrix ligands fibronectin and tenascin collaborate in regulating collagenase gene expression in fibroblasts. Mol. Biol. Cell 5:439-453.

39. Clancy, R., J. Leszczynska, A. Amin, D. Levartovsky, and S.B. Abramson. 1995. Nitric oxide stimulates ADP-ribosylation of actin in association with the inhibition actin polymerization in human neutrophils. J. Leukocyte Biol. 58: 196-202.

40. Jun, C.D., M.K. Han, U.H. Kim, and H.T. Chung. 1996. Nitric oxide induces ADP-ribosylation of actin in murine macrophages: association with the inhibition of pseudopodia formation, phagocytic activity, and adherence on a laminin substrate. Cell. Immunol. 174:25-34.

41. Gopalakrishna, R., Z.H. Chen, and U. Gundimeda. 1993. Nitric oxide and nitric oxide-generating agents induce a reversible inactivation of protein kinase C activity and phorbol ester binding. J. Biol. Chem. 268:27180-27185.

42. Lust, G., and N. Burton-Wurster. 1992. Fibronectin in osteoarthritis: comparison of animal and human diseases. In Articular Cartilage and Osteoarthritis. K.E. Kuettner, J. Peyron, R. Schleyerbach, and V.C. Hoscall, editors. Raven Press, NY. 447-454.

43. Wurster, N.B., and G. Lust. 1982. Fibronectin in osteoarthritic canine articular cartilage. Biochem. Biophys. Res. Commun. 109:1094-1104.

44. Xie, D.L., R. Meyers, and G.A. Homandberg. 1992. Fibronectin fragments in osteoarthritic synovial fluid. J. Rheum. 19:1448-1452. 